\title{
Cultural participation in digital environments: Goals and stakes for Quebec cultural policies
}

\author{
Nathalie Casemajor \\ Urbanisation Culture Société Research Centre, Institut national de la recherche \\ scientifique, Montreal, Canada \\ nathalie.casemajor@ucs.inrs.ca \\ https://orcid.org/0000-0001-7901-4859
}

Guy Bellavance

Urbanisation Culture Société Research Centre, Institut national de la recherche scientifique, Montreal, Canada

Guillaume Sirois

Sociology Department, Université de Montréal, Montreal, Canada

Digital environments have expanded the forms of cultural participation. This paper has two aims: first, to elucidate the changing definitions of cultural participation in relation to digital environments; second, to examine the ways in which cultural policies respond to the new digital conditions of cultural participation. Focusing on Quebec (Canada), this paper is based on a critical review of grey literature in the public policy. We identified three main goals pursued by Quebec cultural policies regarding digital participation: 1) to produce and promote national cultural content; 2) to promote cultural equity; 3 ) to foster digital equity. The analysis shows that these goals partially exceed the scope of cultural policies to intersect with economic, educational, and youth policies. We also argue that policy frameworks and funding programs in support of cultural policies tend to legitimize an overlap of the social, economic, and political dimensions of cultural participation.

Keywords: cultural participation; cultural policy; digital culture; engagement; Quebec; Canada 
The emergence of 'participatory' digital platforms has caused a major upheaval in the cultural sector in the last decade as new forms of cultural participation have appeared: online discussion forums, collaborative encyclopedias, socio-digital networks, applications for sharing text, image, and audio files, and crowdfunding sites. There has been little research on the general response of public authorities to the evolution of cultural participation in the context of digital technologies. Some researchers have explored the European environment (Tomka 2013), but few have looked at North America, where development of cultural policies often follows a different trajectory. Quebec represents a unique case in North America: this majority francophone Canadian province has its own ministry of culture, which promulgates an interventionist policy in terms of support for arts and culture. Research has been conducted on Quebec's digital culture policies (Roberge et al. 2017; Saint-Pierre et al. 2019), but the question of cultural participation has not been explored. Recent investigations of cultural participation, both quantitative (UNESCO Institute for Statistics 2012) and qualitative (Novak-Leonard et al. 2014; Canada Council for the Arts 2012), have addressed the dimension of digital technology only tangentially, from the angle of online cultural consumption (UNESCO Institute for Statistics and ISQ 2017), with a few exceptions (Donnat 2017; Laurent 2015; MTM London 2010).

Here, we therefore undertake a critical analysis of how Quebec cultural policies are responding to the new conditions of digital cultural participation. In doing so, we show how such policy development contributes to legitimizing representations of the public and of cultural participation. These representations fit within a series of overall transformations in the relationship between culture and the digital context. How do cultural policies define digital cultural participation? What aspects of cultural participation receive the most attention in governmental policies, and what policy 
instruments are implemented? Finally, how are the social, economic, and political dimensions of participation rearticulated in this new context? Our corpus of analysis, described below, is drawn from a literature review (Casemajor et al. 2018) on cultural participation in the digital environment produced for the Ministère de la Culture et des Communications du Québec (MCCQ, Quebec Ministry of Culture and Communications).

First, we situate some of the major changes that have occurred in cultural participation with development of the digital environment. We then discuss three main goals of Quebec cultural policies in this area: to produce and disseminate national ${ }^{1}$ cultural content; to encourage cultural equity and diversity; and to encourage digital equity. To conclude, we discuss the main issues raised by the reconfiguration of cultural publics in the digital environment for cultural policies.

\section{1 - Public policy for digital cultural participation}

\subsection{Cultural participation in the digital environment}

Long considered from the limited angle of visits to cultural facilities and calculated by number of visitors, the notion of cultural participation has undergone two major and parallel evolutions in recent decades. First, it has been broadened to include more diversified fields of cultural practice; second, it has been deployed in new contexts linked to the emergence of digital environments.

Beyond mere visitor numbers, the participation of publics in cultural activities is increasingly understood in a broader sense, which makes it possible to include practices traditionally viewed as less legitimate and not as well documented, such as amateur,

\footnotetext{
${ }^{1}$ Quebec has officially considered been a nation by the Canadian Parliament since 2006. Therefore, the term "national" refers to Quebec in the context of this paper.
} 
volunteer, and philanthropic practices (Donnat 2009; Flichy 2010; Hennion et al. 2000), as well as popular culture practices (Burgess et al. 2006). The notion of engagement, increasingly used to update the comprehension of participation (Ivey 2008), stresses a strong investment by participants in experiential, identity-related, and expressive activities that resonate both collectively (social and political connections) and individually (self-development; Octobre 2019).

Today, the issue of public participation in the cultural sector is thus situated at the intersection of economic, social, and political dimensions. Economically, participation is understood not only in terms of cultural consumption but also in the sense of donations to and volunteering at cultural organizations. Socially, cultural participation is envisaged as a vector of integration into a community that shares a common foundation of cultural experiences and references. And politically, citizen participation is one of the conditions of democracy, and the cultural sector is conceived in public policies as a space for citizen engagement in favour of the common good.

At the same time, the advent of a digital cultural regime has brought forth new conditions for participation. The material conditions of this regime concern equipment (computer, smartphone, tablet) and connection to the Internet. New social conditions for cultural participation involve the organization of networked publics (boyd 2008), social connectivity (van Dijck 2013), expressiveness (Allard 2007), and a porous border between private and public. Cultural conditions include content customizing and remixing practices, as well as digital aesthetics and imaginaries. Techno-economic conditions are induced by big-data economies and platform capitalism (Srnicek 2017). Finally, techno-political conditions concern rights and freedoms, redistribution of power between Web behemoths and cultural actors, and the ethics of digital communications. 
These new conditions have given rise to original forms of cultural participation that impact various phases of the process of creation, production, and distribution of cultural products, including crowdfunding, crowdsourcing, redocumentation of artworks (on Wikipedia, for example; Casemajor 2013) and visibility on social networks. Although they are not completely new, these forms have unique characteristics: they amplify mobilization and engagement of the public, while constantly reducing the gap between cultural producer and user and between amateur and professional. This new status for the public as intermediary or cultural link makes the traditional conception of the public as end user obsolete. In addition, it provokes a reorganization of cultural fields, as professionals are encouraged to develop skills to master platforms and amateurs find new paths to professionalization.

In the professional digital communications field, however, the notion of digital engagement is still influenced mainly by work in the field of marketing and public relations (Walmsley 2016). Usually, it designates all online activity by an active consumer who invests (time, money, and attention) in production and promotion of the online cultural offer. This perspective was shaped largely by Toffler's (1980) seminal work on the prosumer, defined as the (re)integration of producer and consumer into a single figure in the 'information age.' The Web 2.0 environment and user-generated content have connected this figure to that of the user of technological devices, engendering the produser (Bruns 2009): a user of digital platforms who not only creates content published online but whose connected usage also provides data on his or her online behaviours.

Finally, participation and digital utopias have also generated their share of critiques. Some authors aim their fire at the 'cult of the amateur' (Keen 2007) and fear a delegitimization of professional practices, given that the public now performs some of 
the financing, communications, and even production tasks previously reserved for technicians and professional intermediaries. Other authors target the work supplied by Internet users free of charge: platform capitalism enterprises count on the participation (more or less voluntary) of Internet users, putting many of them to (unpaid) work and exploiting their personal data for their business models (Terranova 2000; van Dijck 2014). A final group of authors examine the socio-political issues of cultural participation (Valtysson 2010; Jancovich and Bianchini 2013). The weakest forms of participation may instrumentalize one of its dimensions - social, economic, political to the detriment of others (Zask 2011), creating an illusory form of participation that does not contribute to forming active, emancipated subjects (Jancovich 2017; Carpentier 2011).

In short, research on digital cultural participation oscillates between a perspective of more or less complete emancipation of the public of amateurs from professional sectors and one of exploitation of users by platform capitalism. The public is becoming an increasingly strategic actor in development in the cultural sector. For cultural policies, this broadening and complexification of the notion of cultural participation in the digital environment raises the challenge of acting at the intersection of economic, social, and political dimensions in a context of rapid and uncertain mutations.

\subsection{Cultural and digital policies in Quebec}

Given this changing media context, cultural policies have evolved over the past twenty years to encourage the digital transition of the arts and culture sector. In Canada, cultural policies are organized in three main levels of intervention: federal, provincial, 
and municipal. Each level has a different degree of engagement with support for culture and sets different priorities for action in the context of the shift to digital.

Our study concentrates on the province of Quebec, which is unique in Canada: it is distinguished from the other provinces by the breadth of its cultural intervention, which rivals the federal level in its ambitions (Bellavance 2000b). Quebec has its own bodies of cultural governance, including the Ministère de la culture et des communications (MCCQ; Ministry of Culture and Communications). A majority francophone society in a federation of majority anglophone provinces, Quebec also stands out for its policy of affirmation of a distinct culture (Saint-Pierre 2011, 226).

Quebec's cultural policies were first developed around heritage and the arts and then were extended to other areas, such as education and community development, but also - and increasingly since the 1980s - cultural industries (Gattinger and Saint-Pierre 2011) and digital technologies. In 2018, the MCCQ promulgated a new cultural policy that places the issue of cultural participation at the heart of its top strategic orientation. The policy defines cultural participation as 'broad and inclusive' (MCCQ 2018, 18) and as going beyond the economic dimension to encompass the social and political dimensions. The participatory orientation of the Quebec policy counts on transversal collaboration among different sectors - not only cultural but also linked to education, social work, healthcare, and the economy. Quebec's cultural policies first addressed digital technologies via the music sector and digitization of heritage collections between the mid-1980s and the late 1990s (Chantepie 2017). It was only starting in the 2000s, with the advent of Web 2.0, that public participation became an issue in digital development. But we argue that cultural participation, on the one hand, and digital culture, on the other hand, still tend to be treated separately. That is, there are relatively few measures dealing specifically with digital cultural participation. Furthermore, 
although the new policy is based on a broader conception of cultural participation, most of the current digital measures tend to be limited to the perspective of consumption of online cultural products and services.

In 2014, the MCCQ played a prominent role in the Quebec cultural sector's digital transition by creating its Digital Cultural Plan, funded with CA $\$ 100$ million over seven years. This strategy was implemented in part by the ministry and its regional branches (seventeen of them), but beyond that, the policy brought together a collection of targeted measures. The 121 measures in the plan, deployed from 2014 to 2019 (and still being added to), were conveyed mainly through some ten public corporations (museums, theatres, libraries and archives, arts and cultural industries support agencies, public broadcaster), but some were delegated to professional groups and non-profit cultural organizations.

In examining the themes covered under these measures (see Figure 1), we also note that Quebec's Digital Cultural Plan was focused mainly on development of the cultural offer (production, visibility, and influence of Quebec-made content in Quebec, Canada, and internationally) rather than on its audiences. It also targeted, to a lesser extent, research and development and the upgrading of professional skills. Unlike Quebec's new cultural policy (which postdates the creation of the Digital Cultural Plan), these measures dealt with the issue of cultural participation only marginally and vaguely. The theme of youth was the only one to suggest the cultural participation of a target public, but it was related, rather, to development of specialized content and partnerships with the education sector. 


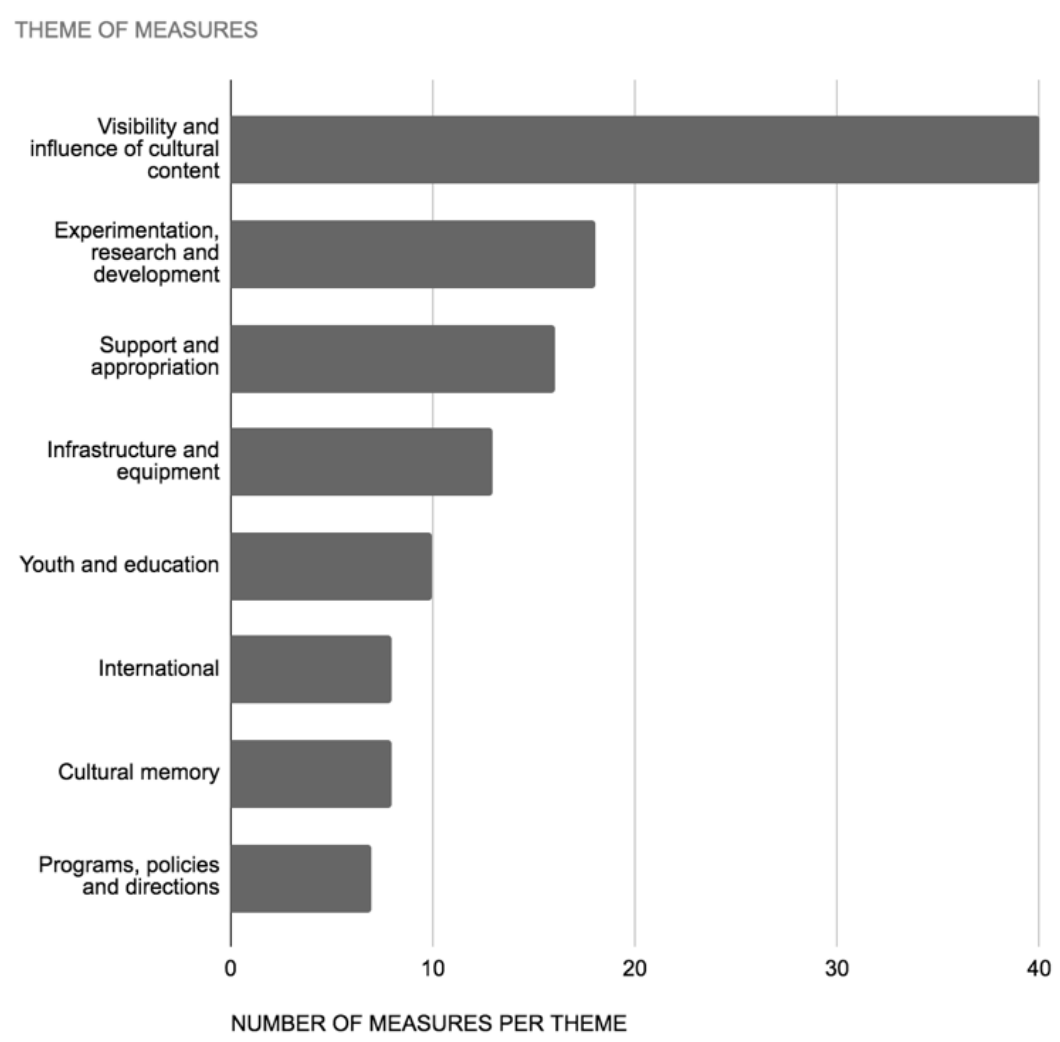

Figure 1: Number of measures in the MCCQ's Digital Cultural Plan classified by theme $(2015-19)$

Aside from the MCCQ, other actors intervene at the local level to contribute to the sector's digital transition and encourage citizens' cultural participation. Cultural actions taken by municipalities, which have increased in numbers since the 2000 s (Breux and Collin 2007) benefit from a funding-agreement mechanism with the MCCQ. For instance, on the municipal level, and notably in the cultural metropolis of Montreal, certain measures to stimulate digital cultural participation are being implemented. They are aimed mainly at developing a local cultural offer, adapted to diverse population groups, families, and young people.

We examine in greater detail below how the transversal nature of digital cultural participation (at the intersection of the social, economic, and political dimensions) is 
embodied in the goals set by cultural policies and how, in part, they go beyond the context of culture to involve other public policy areas, including the economic, education, and youth sectors.

\subsection{Goals of public policies}

Our analysis is based on a review of the grey literature in the public policy sector at the provincial and municipal levels - the levels that are most active in the area of digital cultural participation - between 2014 and 2019. We gathered the literature by exploring the websites of Quebec governments (culture, education, economy), public corporations and agencies devoted to culture and communications, municipalities, and the largest Quebec cultural institutions. We retained sixteen documents (strategic frameworks, policy instruments, grant programs) from the MCCQ, the Ministère de l'Économie, de la Science et de l'Innovation (MESI, Quebec Ministry of the Economy, Science, and Innovation), the Ministère de l'Éducation et de l'Enseignement Supérieur (Quebec Ministry of Education and Higher Education), the Conseil des Arts et des Lettres du Québec (Quebec Council of Arts and Letters), the City of Montreal, Bibliothèque et Archives nationales du Québec (Quebec National Library and Archives), and the Musée de la civilisation (Quebec Museum of Civilization, a public corporation).

Our analysis was enhanced by a series of conversations and observations conducted between October 2017 and June 2018 during knowledge transfer and mobilization workshops with Quebec cultural professionals. The corpus was processed with an inductive content analysis. We took as a point of departure the thematic signposts set out in an international comparative study of digital cultural policies conducted by Nordicity (2016) for the Canada Council for the Arts, and we modified and refined them as we analyzed our corpus by adapting them to the Quebec context. 
The analysis uncovered three main groups of goals, each mobilizing different facets of cultural participation (see Table 1). The first aims to produce and disseminate national cultural content. It concerns mainly cultural consumption and the hybrid figures of the prosumer and produser. Drawing on the idea of Internet users' participation as an engine of economic development, it includes different facets of participation: the engagement of publics as producers and investors (crowdfunding), their role as promotional agents in social media, and their role as suppliers of behavioural data that allow them to be targeted and their tastes to be predicted. By mobilizing these forms of participation, existing cultural policies (especially at the provincial and federal levels) aim to increase the discoverability of Quebec cultural content on the Internet, given the abundance of the offer and the domination of the major international commercial platforms. It is this first group of goals that currently gets the most attention from the Digital Cultural Plan. 
Table 1: Goals of public actions and facets of digital cultural participation in Quebec

\section{GOAL OF CULTURAL POLICY $\quad$ FACET OF DIGITAL CULTURAL PARTICIPATION}

\section{Produce and disseminate 1.1 Publics as producers and investors:}

national cultural content crowdfunding platforms

1.2 Publics as promotional agents: visibility in social media

1.3 Publics as suppliers of behavioural data: micro-targeting and taste prediction

\section{Encourage cultural equity 2.1 Democratization of culture and diversity $\quad 2.2$ Cultural democracy}

\section{Encourage digital equity 3.1 Access to Internet connection}

\subsection{Digital literacy}

\subsection{Diversity of platform uses}

The two other sets of goals - to encourage equity and cultural diversity and to encourage digital equity - are more closely related to the social and political dimensions of participation, and they are dealt with on both the provincial and local scales. In the case of cultural equity, the digital tools are designed mainly as an extension of existing means to mitigate the dynamics of exclusion and estrangement vis-à-vis the cultural field. The logics of action in this sector are based on the well-established political principles of cultural democratization and cultural democracy. As concerns digital equity, governmental action aims to reduce the new forms of inequalities in terms of access to the Internet and skills in using digital tools (digital divides), which impede cultural participation in the digital context. As we shall see, in the first set of goals, 
cultural policies intersect mainly with economic policies. The second set intersects more with youth policies. And the third set, which largely surpasses the context of cultural policies, intersects with both economic and educational policies.

\section{Production and dissemination of national cultural content}

The issue of dissemination and visibility of national cultural productions largely dominates the Quebec approach to digital cultural participation. The logic of action of cultural policies in this sector is situated between national identity policy and economic development measures. The economic nationalism underlying this approach stresses competition for the attention of the online public in the context of a huge volume of foreign material on offer. In this context, the idea is to boost means for producing, marketing, and enhancing the discoverability of Quebec cultural content by relying on the participation of online publics. First proposed by a coalition of representatives from audiovisual sectors, the most directly affected by technological changes (broadcasting, film, and sound recording industries), this logic is now tending to propagate to more traditional cultural sectors (libraries, museums, publishing, theatre, visual arts).

This form of governmental action aims to support, in a mainly economic perspective, the development of skills and tools within local professional circles so that they can highlight their online presence and encourage their publics to support them. In these cases, actions are concentrated around three main mechanisms: crowdfunding of cultural productions, social or relational marketing, and online micro-targeting. Highly different conceptions of participation underlie these mechanisms. The first and second cases involve the participation of engaged users (produsers) or active consumers (prosumers); in the third, participants tend to appear, rather, as more or less voluntary suppliers of behavioural data. 


\subsection{Publics as producers and investors: crowdfunding platforms}

A means of self-production for artists and of diversification of revenue sources for cultural organizations, crowdfunding platforms tend to mobilize the public in advance of cultural projects rather than once they are produced. Participants act as investorproducers rather than as sponsors or philanthropists. Nevertheless, the public's participation is not essentially economic in nature; nor is it stripped of philanthropic aims. Contributors' expectations therefore vary in terms of gratification and return on investment, depending on the value of the financial contribution and the kinds of compensation offered: free tickets, albums, or promotional materials such as posters and t-shirts, premium access to the beta version of a video game, exclusive props in the game, or a share in the profit on sales.

Although success stories do exist (Walmsley 2016), these funding campaigns require considerable effort in terms of time and skills, their costs sometimes surpass the revenues harvested, and the dropout rate of participants seems relatively high. The mobilization of contributors can, in fact, be exhausted before the promotional phase for the product is reached (Galuszka and Brzozowska 2017), as the engagement of the public may be ephemeral if a connection is not maintained throughout the production process. A study conducted on Kickstarter (Rocha 2017), which is the most widely used crowdfunding platform in Canada, shows that its main users are cultural industry sectors (notably video games in Montreal and films and videos in Toronto and Vancouver). That being said, the projects that raised the most money (more than CA $\$ 500,000$ ) belonged to the book-publishing and visual arts sectors, and those showing the best success rates belonged to the dance and theatre sectors. 
The multiplication of these types of platforms and the high proportion of artistic and cultural projects that they generate have led the government of Quebec to become involved financially. Some of its actions concern professional training, via funding of modules that present the available crowdfunding models and explain how to mobilize contributor networks. It also forms partnerships directly with this type of platform. For instance, through its youth secretariat, it formed an alliance with the Quebec platform La Ruche - which defines itself as a 'proximity' participatory fundraising platform - by making available a matching budget ( $\$ 10$ million over five years) to double the contributions gathered. Although this measure was not necessarily aimed at cultural and artistic projects, it was nevertheless found to benefit projects in these sectors: in the case of La Ruche, the proportion of cultural or artistic projects varies between a quarter and a third.

\subsection{Publics as promotional agents: Visibility in social media}

Social media have inaugurated a type of platform that allows for the digital mobilization of the public as promotional agent. Socio-digital networks (Facebook, Twitter, Instagram) and streaming platforms (Youtube, Netflix, Twitch) depend on user activity and recommendations. Now, audiences connected to these media act in aggregate as a vector of 'social' visibility. The visibility of cultural content published in news feeds, recommendation lists, and search results thus depends on users' engagement rates and exposure rates on these platforms.

This visibility takes four main forms, linked to different kinds of participation by the public: 1) the replication of content published on a socio-digital network by an accumulation of likes, sharing of content, comments, and tagging other users; 2) public expression of cultural tastes and consumption preferences (subscribing to artists' 
profiles, curating reading lists on musical and video streaming sites); 3) live sharing and public staging of cultural experiences in an event-based logic (livestreaming parts of video games on Twitch, ephemeral 'stories' on Snapchat or Instagram, live conversations on Messenger or WhatsApp during TV programs); 4) publication of evaluations of the cultural offer (ratings and reviews in the form of numbered scores, videos, podcasts, or posts on blogs and online forums).

According to van Dijck (2013), most commercial platforms share common principles of user rankings that reward those who create or share the most popular content and hide the rest. Use of social media thus enables users to build social capital, forge identity markers, and express these markers in public (Jensen Schau and Gilly 2003). The marketing literature stresses how these forms of expression and social gratification, which combine social interaction with products, can be put to profit in branding strategies: engaging in dialogue with users, spotting influencers, contacting them personally, and encouraging them to relay information is now a privileged 'social publishing' strategy (Ashley and Tuten 2015).

Therefore, in an effort to ensure better visibility and discoverability of the local offer, Quebec cultural policies support the development of communications and marketing aptitudes on socio-digital networks, especially Facebook. Training modules are made available to cultural professionals, including advice on communications strategy, targeting (or profiling) an audience, purchasing online advertising, and aspects of understanding how the content-display algorithms that govern online visibility plans operate.

In this last respect, important efforts have also been made at the Observatoire de la culture et des communications du Québec (Quebec observatory of culture and communications, at the Institut de la statistique du Québec) to encourage different 
production sectors to supply metadata that will enable users to more easily find the Quebec content that they are looking for on the Web. Quebec's Digital Cultural Plan also provides for the creation of a strategic site on this theme within the MCCQ, which gave rise to an action plan (2017) and to a partnership with the Ministry of Culture in France around the discoverability of francophone content (2019).

\subsection{Publics as suppliers of behavioural data: micro-targeting and taste} prediction

At the turn of the 2010s, the participatory Web shifted to business models based on big data. Collected on the scale of mass populations, these data stand out for their large volume, great variety, and velocity, with real-time updating in some cases (De Mauro et al. 2016). The composition of these datasets flows from a growing datafication phenomenon (Mayer-Schoenberger and Cukier 2013) - that is, the capture of traces of humans' activity using Internet-connected tools (mobile phones, computers, watches, and other items in the Internet of objects) to produce digital data subsequently gathered in aggregated databases.

The business model of the major participatory platforms is therefore based on commercialization of the data that document the behaviour of their users. Mass production of behavioural data thus represents a property intrinsic to digital participation. In this paradigm of the data-driven economy, users more nor less contribute to their own datafication, and the participation of publics makes it easier to know and target them. For this reason, this unusual conception of participation is gradually invading professional cultural fields.

Mechanisms have thus been developed in the cultural sector that cross sociodemographic data on publics (age, sex, place of residence, income) with 
behavioural data. The latter may include tastes and cultural preferences (cultural content consumed online classified by gender, ticket sales by type of show, list of books borrowed from the library), but it may also concern purchase intentions inferred from online browsing, types of equipment used to consume cultural content (phone, tablet, computer), travel, real-time consumption thanks to GPS data from phones and RFID chips, and transportation used to go to cultural venues (payment for parking, rental of self-serve bicycles, use of public transit). Aside from micro-targeting and taste prediction of publics in online platforms, these data are used for behavioural marketing, for example in the creation of custom-made experiences, in the wake of the customization movement, or personalized consumption, instigated in the early $1980 \mathrm{~s}$ (Toffler 1980).

As they try to react as best they can to this major transformation in the digital economy, public authorities often seem to be in the thrall of an industry whose technological advances are both rapid and unpredictable. A number of public action challenges that directly concern the cultural field can nevertheless be identified: development of data-analysis skills within artistic and cultural professional fields; pooling of data by cultural organizations to make up for the stranglehold of the big platforms (Google, Facebook, Spotify, Amazon) over datametric profiles of publics; and regulation of the terms of mass data collection to protect the privacy of users and the security of their data (this last issue goes well beyond the cultural sector).

To date, the Quebec government's main action measure in this respect combines the issues of training and data pooling. The MESI and the MCCQ provided funding to a large-scale work site to create an infrastructure for pooling and analysis of cultural data. The work site gave rise to a hub on big data in culture (named Synapse C) created in Montreal in 2018, in partnership with academic marketing researchers. Also supported 
by other provincial and federal agencies, in 2019 Synapse $\mathrm{C}$, intending to position itself as an international reference in the sector, raised more than CA $\$ 2.2$ million.

Inspired by the Audience Agency model set up in 2012 in Great Britain by Arts Council England, the Quebec structure has a more modest ambition. In England, all publicly funded organizations are obliged to place their data in the pooled database, whereas the Quebec project is aimed at voluntary pooling among small groups of partner organizations. Nevertheless, the initiative is aimed, more broadly, at informing the arts and culture sector about the issues in big data analysis and facilitating collaborations between professionals in the sector and data scientists.

Although many culture professionals are enthusiastic about the prospects for exploiting behavioural data, which would allow for detailed analysis of certain niche activities (Hanquinet et al. 2019), these new practices also raise anxieties. They are rejected by some artists as antithetical to their political values and underground positioning (Creton 2018). Others are disturbed about the effects that a possible injunction to collect data might have on art production and dissemination practices. Indeed, these datasets not only produce measurements of public activity but also construct social representations of publics that orient the action of and have effects on professional practices. Furthermore, a large series of factors point to prudence with regard to the terms for adopting this model, notably the tendency to overestimate the capacities of such data analytics tools, particularly by services suppliers and consultants, and ethical drifts in practices that do not systematically protect the personal data of users. 


\section{Equity and cultural diversity: Between democratization of culture and cultural democracy}

Cultural equity is another major goal of Quebec policy with regard to digital cultural participation. In this respect, the theme of democratization of culture represents one of the main justifications for public action in contemporary times, and it has profoundly marked Quebec policies. This logic for action is situated between democratization of 'scholarly' culture, which involves raising awareness of traditional arts, and 'popular' cultural democracy, which aims to include a broader and less 'legitimate' set of content and cultural practices. In this sense, it seems to contain a component of tension - or even ambivalence - between top-down and bottom-up measures (Bellavance 2000a).

This logic for action, which is intended to be simultaneously democratizing and democratic, nevertheless remains a regulatory utopia for cultural policies.

Democratization, understood in this way, involves the double aim of socialization of the arts and $b y$ the arts. The emergence of the digital environment and the increased use of participatory platforms have now been spontaneously linked to the arsenal of measures aiming to reach this goal, both as a means of raising awareness of the arts and as a means of inclusion of emerging cultural practices and content. Thus, by seeking to encourage both diversification of cultural content and publics for culture, the goal of cultural equity intersects with that of cultural diversity.

This logic for action is also linked to unique conceptions of cultural participation, corresponding to certain ideal-typical figures of the public. In response to the 'engaged user' (agent of production and dissemination of content) emerges the ‘erudite citizen' - amateur yet expert, member of a broad, universal, or universalizable community of taste. Here, publics are envisaged from the angle of citizenship and community rather than the market; their mobilization proceeds from the affirmation and 
development of cultural rights (and responsibilities). These citizen and community perspectives therefore stress the political dimension of cultural participation and are usually justified by the quest for the common good.

Nevertheless, this goal of public action seems to be in retreat or sidelined, even withdrawn, in the face of the primarily economic or commercial production and discoverability goals that currently predominate in digital cultural policies. In fact, the number and extent of support measures specifically destined for equity and cultural diversity seem relatively modest, or more diffuse, in Quebec. As digital platforms and peer-to-peer networks emerge, the general attitude toward 'digital democratization' has seemed purely defensive: the fight against piracy and illegal appropriation of cultural content falls within a rhetoric of strictly commercial antagonism, setting rights holders and users, producers and consumers, at odds. In this context, the political and social aspects of digital cultural participation are swept under the rug.

This reaction may seem surprising given the range and wealth of possible modes of participation when it comes to democratization of culture and cultural democracy. Aside from the case of Wikipedia - an exemplary form of commons-based peer production (Benkler 2006) - numerous evaluation, collection, curating, and creation practices are available to a broad public of potential experts and amateurs: contributions to the documentation of patrimonial collections put online by institutions, production of visual memes from these collections, fan fiction and remixes of existing works (often considered piracy), amateur creation solicited by contests, and co-creation of works in interaction with artists.

The main digital cultural democratization measures in Quebec are currently being taken from the MCCQ's Digital Cultural Plan, through which some non-profit organizations have come to play a structural role with regard to digital cultural 
participation. This is the case for Culture pour tous, an organization that the MCCQ has mandated to create an incubator for 'innovative digital projects that encourage access to and participation in culture.' The organization's programs are articulated around two areas: education and discoverability. Although a number of the projects supported by this measure were produced in partnership with the education sector, the accent on discoverability also anchored this initiative in the economic perspective of market development.

The cultural development agreements concluded between the MCCQ and municipalities are another decentralization mechanism favouring democratization and cultural democracy. This local scale lends itself well to actions linking awareness raising, digital culture, and participants' creative expression. The City of Montreal is an important player in the development of such projects. Its 2017-2022 Cultural Development Policy prioritizes action to 'support the cultural mediation initiatives designed to stimulate the public's participation in the development of digital culture' (Ville de Montréal 2017, 61). In this perspective, the city's cultural services developed a grant program (Médiations culturelles MTL) for projects by cultural and artistic organizations aimed at developing citizens' expression by digital means.

A section of the program called 'participatory digital culture' focuses more specifically on supporting 'cultural initiatives that integrate digital technologies and encourage Montrealers' participation in and contribution to digital arts and creativity' (Ville de Montréal 2018, our translation). Projects supported by the program must be aimed at developing partnerships between cultural and artistic organizations and schools or socio-community organizations (social centres, seniors' residences, homeless shelters, and others) so as to form collaborative networks in the city. These projects therefore address 'target' audiences in the sense of groups with specific guidance needs 
(young people, 'vulnerable' or 'marginalized' groups). Clearly, the objective is to create social ties within a community anchored in a local territory.

Therefore, on the scale of municipal policies, the social and political dimension of cultural participation is overtly encouraged, with little or no reference to market development. In contrast, in the policies and measures initiated at the provincial level, the economic, social, and political dimensions of participation tend to intersect more closely. For instance, the inter-ministerial Stratégie numérique du Québec (Quebec Digital Strategy), formulated in 2017 and led by the MESI, juxtaposed these dimensions in formulations that were sometimes surprising. The document brought together in a single sentence cultural mediation (which designates, in the francophone world, forms of guidance and education of publics) and the 'targeting' of participants by the use of 'data on cultural content.' Certainly, cultural mediation develops actions adapted to the needs of target groups, and detailed knowledge of the characteristics of the public make it possible to deduce which non-publics to reach through cultural mediation actions. In the field, however, cultural mediation and data targeting are deployed in very different logics of action; the former is related to an educational, or even social work, mission, whereas the latter is based on marketing segmentations for market development.

More broadly, the emphasis that the Stratégie numérique du Québec places on data targeting shows that the algorithmic conception of the public now extends to the perspectives of cultural democratization and democracy. Similarly, the pedagogical action of 'raising awareness' or education in culture seems just as inseparable from the commercial logic of discoverability of Quebec cultural products. What arises from this association - or even conflation - of economic and social intentions is a certain blurring between commercialization and democratization, in which the latter is not necessarily the better served. 


\section{Digital divides, technological equity, and education}

The struggle against unequal access to and use of technologies is distinct from issues of cultural equity alone. The search for digital equity is a third goal of public action with regard to digital cultural participation. In this respect, scientific research generally identifies three types of 'digital divides' (Haight et al. 2014). The first concerns the Internet connection rate; the second, levels of skill and comfort developed with digital tools (digital literacy); and the third, the differentiation of cultural uses once these obstacles have been vanquished (especially gender differentiation).

The first two types concern technological issues that are outside the mandate of government ministries responsible for culture and therefore beyond the perimeter of traditional cultural policies, which complicates the implementation of targeted cultural policies. Although the first divide is well defined, the second one clearly remains a moving target. The last type of divide is generally not considered in cultural policies, including in Quebec.

In Northern countries, the connection divide was greatly reduced as the mobile Internet spread. In Quebec, 93 percent of households were connected in 2019 (CEFRIO 2019). But a new cleavage appears when it comes to high-speed access: easy in urban regions, it remains problematic in rural and remote regions, notably in Indigenous communities. As for the skills divide, caused by cumulative inequality effects, it remains very deep (Casemajor et al. 2018).

Although younger generations are, on the whole, more at ease with digital technologies than their elders are, the capacities of all age groups are affected by low socio-economic status. The idea of digital natives is therefore a myth: young people do not all have equal mastery of these technologies. Indeed, the digital inequality factors 
are cumulative: young graduates and upper-middle-class students in an urban environment have more advanced and diversified digital practices; low-income older people living in rural areas and Indigenous people are disadvantaged. Therefore, digital divides represent new forms of inequality specific to the digital context, but they also reproduce or reinforce pre-existing inequalities based on unequal transmission of capital (social, economic, and cultural).

The connection divide is a result mainly of economic and industrial policies, and the few measures aimed at access to culture are directed toward producers and distributors, without directly addressing the question of publics and their participation. The skills divide, related to level of digital literacy, is covered mainly in education policies, a jurisdiction that falls principally to the provinces in Canada.

Digital literacy is one of the highest priorities identified by Quebec's 2017 digital strategy: it is even defined as its second strategic target. This target is accompanied by the Digital Action Plan for Education and Higher Education, which is both well endowed (CA\$1.2 billion for the 2018-23 period) and highly structured, including a reference framework for 'digital competency' (MEES 2019), which is defined as the 'ability to find, organize, understand, evaluate, create and disseminate information using digital technology' (MEES 2019, 28). The framework also offers a broader definition than simple technological mastery: it includes skills that are social, collaborative, cognitive, ethical, and citizenship-related, which are among the 'twentyfirst-century skills' promoted by the OECD.

Articulated around twelve dimensions, the framework also encourages a distancing from digital technology issues, or even a critique of conditions for participation. One dimension in particular involves the development of critical thinking regarding the benefits and limitations of digital technology; another, which encourages 
'ethical citizenship,' sets out to promote comprehension of 'the issues around the commodification of personal information [and] the influence of digital advertising' (MEES 2019, 13). This last dimension is audacious and extremely important, given that collection of personal information is a central issue in recent ethical scandals linked to the platform capitalism model. Cultural participation is not, however, a specific dimension in this reference framework.

More generally, the arts and culture sector is not identified as a privileged field of action for the development of digital literacy. Rather, it is assimilated with the ‘innovation and creativity’ dimension, alongside project development and entrepreneurship, which dilutes the specificity of arts and culture into more general categories and minimizes the intellectual and cognitive aspects of cultural practices. Favouring digital literacy does not, in fact, necessarily involve cultural literacy. The relationship between education and culture remains problematic from this point of view.

The few digital literacy policies and measures that deal specifically with publics for culture come from the MCCQ. Although Quebec's new cultural policy includes digital literacy in its first objective, the resulting measures were in fact concentrated mainly on literacy among professional circles. The Digital Cultural Plan, for its part, does lay out measures for young people and education, but these are aimed essentially at the production of youth content. Ultimately, once again, the majority of digital literacy interventions for cultural publics are deployed at the level of communities, associations, and local institutions (municipalities, libraries and museums, cultural organizations).

In these areas, the Fab Lab and media lab model stands out as the main channel for teaching digital skills in the context of artistic and cultural creation. Emerging from the associative field and the technological sector, these digital creation and experimentation laboratories have gradually been extended into the cultural and school 
sectors over the last decade. Few art-related non-profit organizations have the resources to equip themselves with such laboratories, or they reserve these facilities for the exclusive use of professional artist members. Some, however, have developed projects by partnering with schools, more and more of which in Quebec are acquiring such equipment. More recently, large national institutions in the library and museum sector have acquired media labs, with support from the private sector. Public investments have also been noted at the municipal level, notably by Montreal in the public library network.

In terms of territorial equity, the vast majority of initiatives are concentrated in the Montreal and Quebec City metropolitan regions. Under the impetus of the action plan for education, Quebec schools are tending to expand the perimeter of Fab Labs and media labs to larger territories, but this equipment remains out of reach for young people who are not in school and for adults in rural regions. Young people not in school and living in rural regions now seem to be one of the most disadvantaged groups from the viewpoint of public actions encouraging digital cultural literacy.

Therefore, a number of socio-economic variables must be taken into account in the struggle against digital inequalities. Although age and schooling are generally seen as factors that determine participation, several others of a physical, geographical, ethnocultural, and linguistic nature are also worth consideration. For instance, what about accessibility for disabled people? Are there important variations in access and use by ethno-linguistic groups and in different waves of immigrants? These questions, which are beyond the scope of this article, are worth further exploration in future research. 


\section{Discussion and conclusion}

Our analysis of public policies recently adopted by Quebec's major agencies and ministries responsible for supporting arts and culture show that public authorities are under pressure to steer the digital transition in such a way that the cultural ecosystem built in recent decades can adapt to this new environment. The emphasis is mainly on production and dissemination of the cultural offer so as to protect a certain national cultural sovereignty by resisting an overabundance of online content, perceived as a form of invasion by globalized commercial culture. Furthermore, the new policies are intended to enable traditional cultural institutions to modernize in order to provide their publics with updated cultural experiences. Technologies are thus perceived both as a possible source of audience development, notably among adolescent publics who are notoriously difficult to reach, and as a means of creating loyalty among current publics who are increasingly attracted to the digital cultural offer.

Given this situation, the Quebec government has undertaken to formulate cultural policies that deal with cultural participation in the digital environment. In this vast area, the government's action is articulated around three main goals: production and dissemination of Quebec cultural content, the emergence of greater cultural equity through extension of the logics of democratization and cultural democracy, and deployment of greater digital equity among citizens. Yet, the three goals pursued by these digital cultural policies also reveal a tension between civic logic and commercial logic (Boltanski and Thévenot 2006): the former targets equity and social justice by encouraging greater citizen participation in cultural life, whereas the latter targets commercialization of cultural products and services by seeking to develop the clientele for Quebec cultural producers and organizations. 
Civic and commercial policies are not necessarily contradictory and may even complement each other. In the cultural sector, however, their association invariably raises some friction and adjustments with regard to the objectives pursued. This tension is not new in the field of Quebec cultural policies, as it was already evident even in Quebec's initial cultural policy, adopted in 1992, which made a first attempt to create a balance between civic and commercial logics.

Nevertheless, with the development of digital environments, new intersections are occurring between these two logics within cultural policies. Indeed, the digital universe feeds both great hopes at the democratic level and great commercial opportunities. The porosity between these logics may thus be a source as much of new forms of civic engagement as of new modes of commercial instrumentalization. On the one hand, much research in the fields of media studies and cultural studies has shown that cultural consumption practices, including digital entertainment, may give rise to critical appropriation of content or to civic mobilization (Jenkins 1992; Brough and Shresthova 2012). On the other hand, the overlapping of these logics in the symbolic and affective Web economy has been conveyed by the celebration of the terms, today tarnished, of 'sharing' and 'participatory,' which are used to justify both the grassroots model of Wikipedia and the neoliberal model of Uber.

In all three goals of public action identified in Quebec, the civic and commercial logics intermingle in mechanisms that rearticulate the social, economic, and political dimensions of participation. On the one hand, this context in transformation has allowed for the emergence of innovative practices and mechanisms (crowdfunding, user recommendations, sharing of free-licence resources), forcing professional fields to reorganize to better account for the new context of participation by publics. Often, civic and commercial logics intersect subtly and inseparably in this environment, sowing 
confusion among different values associated with cultural participation. On the other hand, a certain number of these mechanisms lead inexorably toward commercial instrumentalization of democratic ideals, notably when it comes to branding in social media and profiling of publics.

Although the first goal identified, which targets production and spread of Quebec culture, is more clearly associated with commercial logics, market-development rationale nevertheless are observed to intersect with those of citizen engagement. A conception of participation understood as 'engagement' of publics does not exclude putting people to work as co-producers of works or distribution agents to encourage the discoverability of Quebec cultural products. Furthermore, the digital participation of publics is actually a potential source of economic development, as the data generated by online activity can themselves be monetized.

Conversely, the second goal, which is anchored more directly in civic logics, through a set of measures encouraging mediation of arts and culture, is not exempt from commercial logics either. Indeed, cultural mediation operations can also be envisaged as a way of targeting publics with the goal of improving visit frequency and marketing strategies. The latter goal is found precisely at the intersection of the two logics, civic and commercial - or, rather, industrial, in the grammar of Boltanski and Thévenot - as it concerns the expertise of actors and the effectiveness of practices. Indeed, this goal aims specifically to encourage people to connect and to develop their expertise with regard to digital tools - an essential prerequisite for their participation, whether as citizens or as consumers.

Thus, beyond the citizen-consumer dichotomy, polysemic notions of cultural participation and citizen engagement generate a series of ambiguities with regard to the types of practices that public policies seek to stimulate: is the idea to kindle monetary 
investment among publics on crowdfunding sites? To increase the numbers of 'likes' and the sharing of content on social media? To develop a taste for an art form or a national cultural repertoire? To diversify forms of cultural expression and amateur practices? These ambiguities are amply reproduced and maintained by public policies, in particular at the level of the Quebec government, which is more connected to commercial and industrial issues.

Another observation is that Quebec cultural environments have a strong propensity to use terminology related to business and marketing when the time comes to talk about digital projects. The vocabulary chosen in public policy documents nevertheless seems sufficiently broad to incorporate certain of the MCCQ's historical preoccupations concerning participation (democratization and cultural democracy), while remaining vague enough to encompass, without differentiation, a number of new practices that are emerging with digital technologies but have considerably varying levels of investment (in money, time, and value). Similarly, the term 'discoverability,' which was on everyone's lips in the Quebec cultural sector in recent years, is ambiguous enough to assemble all cultural actors, without regard for their aims, around this project, which seeks, above all, to propagate the national culture.

Finally, it can be noted that the project to develop cultural participation through digital technologies reaches far beyond the traditional jurisdiction of the MCCQ and its public corporations to involve multiple components of the governmental apparatus. For instance, measures targeting the development of a digital economy fall essentially under the ministry responsible for the economy; measures to increase digital literacy are implemented by the ministry of education; and a reduction in digital divides involves a range of stakeholders, including authorities responsible for industrial infrastructure, 
which falls mainly under federal jurisdiction. The result is a set of implicit cultural policies (Ahearne 2009) that are made necessary by the digital environment.

With its digital cultural policies, the MCCQ is therefore updating one of its historical ambitions - that of making culture a transversal field of action of the Quebec government. Indeed, although cultural policies have generally retained some autonomy, or even siloed development (performing arts and film policies, for example), the national strategic frameworks are increasingly identifying arts and culture as a field that should involve a number of players around the Cabinet table. Yet, in this context, we may wonder how a ministry of culture can contribute specifically to citizens' online participation, compared to contributions by other ministries in this area.

Actions in favour of greater cultural equity appear no doubt to be the most obvious response, as this has been one of the MCCQ's primary missions since its inception. Yet cultural equity remains an ideal that is difficult to grasp in the decompartmentalized universe of digital technologies, which explains in part its current lack of visibility compared to commercial and industrial missions, the immediate effects of which are easier to measure. And yet, in terms of cultural equity, digital technologies open up a new field of experimentation abandoned by the Internet giants (exemplified by Google, Apple, Facebook, Amazon, and Microsoft), which the public authorities could seize upon more boldly.

This work was supported by the Fonds de recherche du Québec - Société et Culture in collaboration with the Ministère de la Culture et des Communications du Québec. The project was conducted in partnership with Culture pour tous and Compétence Culture. The authors would like to acknowledge the research assistants who participated in the 
review of the literature - Martine El Ouardi, Romuald Jamet, Morad Jeldi, and Annie Perron - as well as Kathe Roth for her translation.

\section{REFERENCES}

Ahearne, Jeremy. 2009. "Cultural Policy Explicit and Implicit: A Distinction and Some Uses." International Journal of Cultural Policy 15 (2): 141-153.

Allard, Laurence. 2007. "Émergence des cultures expressives, d'internet au mobile" [Emergence of expressive cultures, from the Internet to mobile]. Médiamorphoses 21: $19-25$.

Ashley, Christy, and Tracy Tuten. 2015. "Creative Strategies in Social Media Marketing: An Exploratory Study of Branded Social Content and Consumer Engagement.” Psychology \& Marketing 32 (1): 15-27. doi:10.1002/mar.20761.

Bellavance, Guy. 2000a. "La démocratisation, et après?" [Democratization, and then?], in Démocratisation de la culture ou démocratie culturelle? Deux logiques d'action publique [Democratization of culture or cultural democracy? Two logics of public action], edited by Guy Bellavance, 11-25. Quebec City: Éditions de 1'IQRC/Presses de l’Université Laval.

Bellavance, Guy. 2000b. "Quebec Cultural Policies.” The Canadian Encyclopedia, https://www.thecanadianencyclopedia.ca/en/article/quebec-cultural-policies. 
Benkler, Yochai, and Helen Nissenbaum. 2006. "Commons-based Peer Production and Virtue." Journal of political philosophy 14 (4): 394-419.

Boltanski, Luc, and Laurent Thévenot. 2006 [1991]. On Justification: Economies of Worth. Translated by Catherine Porter. Princeton, NJ: Princeton University Press, 2006.

boyd, danah. 2008. Taken Out of Context: American Teen Sociality in Networked Publics. Berkeley: UC Berkeley.

Breux, Sandra, and Jean-Pierre Collin. 2007. "La politique culturelle des villes québécoises face à la récente réforme municipale" [The cultural policy of Quebec cities in response to the recent municipal reform]. Cahiers de géographie du Québec 51 (142): 9-27.

Brough, Melissa M., and Sangita Shresthova. 2012. "Fandom meets Activism: Rethinking Civic and Political Participation." Transformative Works and Cultures 10: $1-2$.

Bruns, Axel. 2009. "From Prosumer to Produser: Understanding User-Led Content Creation." Paper presented at Transforming Audiences 2009, September 3-4, 2009, London.

Burgess, Jean E., Marcus Foth, and Helen G. Klaebe. 2006. "Everyday Creativity as Civic Engagement: A Cultural Citizenship View of New Media.” In Proceedings 2006 
Communications Policy \& Research Forum, edited by F. Papandrea, 1-16. Sydney: Network Insight Institute.

Canada Council for the Arts. 2012. Public Engagement in the Arts - Discussion Paper. Ottawa: Canada Council for the Arts.

Carpentier, Nico. 2011. "The Concept of Participation: If They Have Access and Interact, Do They Really Participate?" CM - Communication Management Quarterly, 6 (21): 13-36.

Casemajor, Nathalie. 2013. "Sortir le musée de sa réserve. La dissémination des collections sur Wikipédia" [Taking the museum out of its reserve: The dissemination of collections on Wikipedia]. In Les visiteurs photographes: un outil pour penser le musée [Visiting photographers: A tool for thinking about the museum], edited by Serge Chaumier, Anne Krebs, and Mélanie Roustan, 52-65. Paris: La Documentation française.

Casemajor, Nathalie, Guy Bellavance, and Guillaume Sirois. 2018. Pratiques culturelles numériques et plateformes participatives. Opportunités, défis et enjeux [Digital cultural practices and participatory platforms: Opportunities, challenges, and issues]. Research report. Montreal: INRS.

CEFRIO. 2019. Portrait numérique des foyers québécois de l'enquête NETendances 2019 du CEFRIO [Digital portrait of Quebec households from CEFRIO's NETendances 2019 inquiry]. Quebec City: CEFRIO. 
Chantepie, Philippe. 2017. "The Shaping of France's Digital Cultural Policy.” Journal of Arts Management, Law, and Society 47 (5): 313-321.

Creton, Caroline. 2018. "To pay or not to pay: les musiciens à notoriété locale face à la publicité ciblée sur Facebook" [To pay or not to pay: Locally popular musicians faced with Facebook's targeted advertising]. Les Enjeux de l'information et de la communication [Information and communications issues] 2: 15-28.

De Mauro, Andrea, Marco Greco, and Michele Grimaldi. 2016. “A Formal Definition of Big Data Based on its Essential Features.” Library Review 65 (3): 122-135.

Donnat, Olivier, ed. 2017. Les publics in situ et en ligne. Culture et recherche [Audiences in situ and online: Culture and research], 134. Paris: Ministère de la Culture et de la Communication.

Donnat, Olivier. 2009. Les pratiques culturelles des Français à l'ère numérique: enquête 2008 [French cultural practices in the digital age: 2008 inquiry]. Paris: La Découverte.

Flichy, Patrice. 2010. Le sacre de l'amateur. Sociologie des passions ordinaires à l'ère numérique [The coronation of the amateur: Sociology of ordinary passions in the digital age]. Paris: Seuil. 
Galuszka, Patryk, and Blanca Brzozowska. 2017. "Crowdfunding and the Democratization of the Music Market." Media, Culture \& Society, 39 (6): 833-849.

Gattinger, Monica, and Diane Saint-Pierre, eds. 2011. Les politiques culturelles provinciales et territoriales du Canada: origines, évolutions et mises en ouvre [Provincial and territorial cultural policies in Canada: Origins, evolutions, and implementations]. Quebec City: Presses de l’Université Laval.

Haight, Michael, Anabel Quan-Haase, and Bradley A. Corbett. 2014. "Revisiting the Digital Divide in Canada: The Impact of Demographic Factors on Access to the Internet, Level of Online Activity, and Social Networking Site Usage.”Information Communication \& Society 17 (4): 503-519.

Hanquinet, Laurie, Dave O’Brien, and Mark Taylor. 2019. “The Coming Crisis of Cultural Engagement? Measurement, Methods, and the Nuances of Niche Activities." Cultural Trends 28 (2-3): 198-219. doi:10.1080/09548963.2019.1617941.

Hennion, Antoine, Sophie Maisonneuve, and Emilie Gomart. 2000. Figures de l'amateur: formes, objets, pratiques de l'amour de la musique aujourd'hui [Figures of the amateur: Forms, objects, and practices of music lovers today]. Paris: La documentation française.

Ivey, William. 2008. "Introduction. The Question of Participation.” In Engaging Art: The Next Great Transformation of America's Cultural Life, edited by William Ivey and Steven J. Tepper, 1-14. London: Routledge 
Jancovich, Leila. 2017. “The participation myth.” International Journal of Cultural Policy 23 (1): 107-121.

Jancovich, Leila, and Franco Bianchini. 2013. "Problematising participation." Cultural Trends 22 (2): 63-66. doi:10.1080/09548963.2013.783158.

Jensen Schau, Hope, and Mary Gilly. 2003. "We Are What We Post? Self-presentation in Personal Web Space.” Journal of Consumer Research, 30: 385-404.

Jenkins, Henry. 1992. Textual Poachers: Television Fans and Participatory Culture. London: Routledge.

Keen, Andrew. 2007. The Cult of the Amateur: How the Democratization of the Digital World is Assaulting our Economy, our Culture, and our Values. New York: Doubleday Currency.

Laurent, Roxane. 2015. Pratiques culturelles en ligne, en France et en Europe. Points de repère et de comparaison 2007-2014. Culture Chiffres, 2 [Online cultural practices in France and Europe: Points of reference and comparison 2007-14. Culture in numbers, 2]. Paris: Ministère de la Culture et de la Communication.

Mayer-Schoenberger, Viktor, and Kenneth Cukier. 2013. Big Data: A Revolution that Will Transform How We Live, Work, and Think. London: John Murray Publishers. 
MCCQ (Ministère de la Culture et des Communications du Québec). 2018. Partout, la culture [Culture everywhere]. Quebec City: MCCQ.

MCCQ (Ministère de la Culture et des Communications du Québec). 2012. La politique culturelle du Québec: Notre culture, notre avenir [Quebec's cultural policy: Our culture, our future]. Quebec City: MCCQ.

MTM London. 2010. Digital Audiences: Engagement with Arts and Culture Online. London: Arts \& Business/Arts Council England/Museums, Libraries \& Archives.

MEES (Ministère de l'éducation et de l'enseignement supérieur du Québec). 2019. Digital Competency Framework. Quebec City: MEES.

Nordicity. 2016. The Arts in a Digital World-Literature Review. Final Report. Ottawa: Canada Council for the Arts.

Novak-Leonard, Jennifer, Patience Baach, Alexandra Schultz, et al. 2014. The Changing Landscape of Arts Participation: A Synthesis of Literature and Expert Interviews. Chicago: NORC/Cultural Policy Center at University of Chicago/National Endowment for the Arts.

Octobre, Sylvie. 2019. "Dégagement, participation et engagement culturel des jeunes: des concepts pour une problématique mouvante" [Young people's cultural detachment, participation, and engagement: Concepts for a shifting issue]. Revue Jeunes et Société 4 (1): $58-76$. 
Roberge, Jonathan, Lyne Nantel, and Andreanne Rousseau. 2017. "Who Needs a Plan Anyway? Digital Cultural Policymaking as the Art of Navigating through Uncertainties." Journal of Arts Management, Law, and Society 47 (5): 300-312.

Rocha Roberto. 2017. "Voici le portrait du sociofinancement au Canada" [Here is the crowdfunding portrait of Canada]. Ici Radio Canada, https://ici.radiocanada.ca/nouvelles/special/2017/04/kickstarter-indiegogo-projets-campagnessociofinancement-entrepreneurs-web/index.html, accessed February 5, 2020.

Saint-Pierre, Diane, Véronique Guèvremont, and Colette Brin. 2019. Le rôle de l'État et des médias dans la promotion de la diversité des expressions culturelles à l'ère du numérique: un état des connaissances et des avancées [The role of the state and the media in promoting the diversity of cultural expressions in the digital age: A report on knowledge and advances]. Montreal and Quebec City: Institut national de la recherche scientifique and Université Laval.

Srnicek, Nick. 2017. Platform capitalism. Hoboken: John Wiley \& Sons.

Terranova, Tiziana. 2000. "Free labor: Producing culture for the digital economy." Social Text 18 (2): 33-58.

Tomka, Goran. 2013. "Reconceptualizing cultural participation in Europe: Grey literature review." Cultural Trends 22 (3-4): 259-264. 
Toffler, Alvin. 1980. The Third Wave. New York: Bantam Books.

UNESCO Institute for Statistics. 2012. Measuring Cultural Participation. Montreal:

UNESCO Institute for Statistics.

UNESCO Institute for Statistics and ISQ (Institut de la statistique du Québec). 2017. Proceedings of the international symposium on the measurement of digital cultural products. Montreal: UNESCO/Institut de la statistique du Québec.

Valtysson, Bjarki. 2010. "Access Culture: Web 2.0 and Cultural Participation.” International Journal of Cultural Policy 16 (2): 200-214.

Van Dijck, José. 2014. “Datafication, dataism and dataveillance: Big Data between scientific paradigm and ideology." Surveillance \& Society 12 (2): 197-208.

Van Dijck, José. 2013. The Culture of Connectivity: A Critical History of Social Media. Oxford: Oxford University Press.

Ville de Montréal. 2018. "La médiation culturelle à la Ville de Montréal” [Cultural mediation in the City of Montreal]. Montréal Médiation culturelle, http://montreal.mediationculturelle.org/soutien-financier/, accessed February 5, 2020.

Ville de Montréal. 2017. Montréal, Cultural Metropolis Combining Creativity and the Citizen Cultural Experience in the Age of Digital Technology and Diversity, the 20172022 Cultural Development Policy. Montréal: Service de la culture, 
http://ville.montreal.qc.ca/culture/sites/ville.montreal.qc.ca.culture/files/2017-

2022_cultural_development_policy_0.pdf, accessed 6 March 2020.

Walmsley, Ben. 2016. "From Arts Marketing to Audience Enrichment: How Digital

Engagement Can Deepen and Democratize Artistic Exchange with Audiences." Poetics 58: $66-78$.

Zask, Joëlle. 2011. Participer. Essai sur les formes démocratiques de la participation

[Participating: Essay on the democratic forms of participation]. Paris: Le Bord de l'eau. 